\title{
Dois ângulos para uma análise da projeção regional brasileira: a visão do Departamento de Estado norte-americano e a questão brasiguaia*
}

\author{
wo Angles of an Analysis of the Brazilian \\ Regional Projection: The View of the US State \\ Department and the "Brasiguayan" Question
}

Fabio Luis Barbosa dos Santos**

Recibido: 12/04/2015

Aprobado: 19/03/2015

Disponible en linea: 30/11/2015

\section{Resumo}

Este texto problematiza o sentido da projeção regional brasileira na atualidade, examinando por um lado a visão dos Estados Unidos sobre o tema, e por outro, as implicações da crise política recente no Paraguai. Para realizar este objetivo, o texto contempla três movimentos. Inicialmente é abordado o contexto em que ressurgem projetos de integração regional americana nos anos 1990. A seguir, são analisados pronunciamentos emanados do Departamento de Estado dos Estados Unidos relacionados

\section{Resumen}

Este texto problematiza el sentido de la proyección regional brasileña en la actualidad, examinando por un lado la visión de Estados Unidos sobre el tema, y por otro, las implicaciones de la crisis política reciente en Paraguay. Para alcanzar este objetivo, el texto contempla tres movimientos. Inicialmente se aborda el contexto en que resurgen proyectos de integración regional americana en los años 1990. En seguida, se analizan pronunciamientos emanados del Departamento de Estado de los Estados Unidos

\section{Abstract}

This article discusses the meaning of Brazil's current regional projection, assessing in one hand the vision that the United States has about this issue and on the other hand the political implications of the recent political crisis in Paraguay. The text unfolds through three steps. At first we focus on the context in which projects of regional integration in the Americas re-emerge in the 1990s. Then we analyse statements of the United States State Departament related to this matter. At last, we discuss the relations

doi: 10.11144/Javeriana.papo20-2.daua

${ }^{*}$ Artículo de reflexión

** Doutor em História Econômica pela Universidade de São Paulo. Professor do Curso de Relações Internacionais da Escola Paulista de Economia, Política e Negócios da Universidade Federal de São Paulo. 
ao tema. Por fim, são abordadas as relações entre o estado brasileiro e o Paraguai, focalizando a questão dos brasiguaios, como estudo de caso que explicita os paradoxos da diplomacia brasileira na região. Nossa hipótese é que a aproximação entre o modo como a projeção regional brasileira é interpretada pelo poder hegemônico no continente, e a incidência deste movimento em um país no qual a influência brasileira está historicamente enraizada, oferece indícios relevantes para avaliar o sentido da integração regional liderada pelo Brasil no subcontinente na atualidade, problematizando a noção de que este processo contradiz o interesse dos Estados Unidos e aponta para um novo padrão de desenvolvimento.

\section{Palavras-chave:}

iniciativa para a integração regional Sul-Americana; União de Nações Sul-Americanas; Integração regional; brasiguaios relacionados al tema. Por fin, se abordan las relaciones entre el Estado brasileño y Paraguay, focalizando la cuestión de los brasiguayos como un estudio de caso que explicita las paradojas de la diplomacia brasileña en la región. Nuestra hipótesis es que la aproximación entre el modo como la proyección regional brasileña es interpretada por el poder hegemónico en el continente y la incidencia de este movimiento en un país en el que la influencia brasileña está históricamente articulada, ofrece indicios relevantes para evaluar el sentido de la integración regional liderada por Brasil en el subcontinente en la actualidad, problematizando la noción de este proceso que contradice el interés de Estados Unidos y apunta hacia un nuevo patrón de desarrollo.

\section{Palabras clave}

iniciativa para la integración regional suramericana; Unión de Naciones Suramericanas; integración regional; brasiguayos between the Brazilian State and Paraguay, focusing on the brasiguaios issue as a case study that illustrates the paradoxes faced by the Brazilian diplomacy in the region. My hypothesis is that as we approach both the way that Brazil's regional projection is seen by the hegemonic power in the continent and the consequences of this movement in a country where Brazilian influence is historically sensitive, offers important evidence to evaluate the meaning of the ongoing regional integration process led by Brazil in the subcontinent, questioning the notion that this process contradicts United States' interests and points to a new pattern of development.

\section{Keywords}

initiative for the integration of the regional infrastructure of South America; Union of South American Nations; regional integration; brasiguaios

\section{Cómo citar este artículo:}

Barbosa dos Santos, L. F. (2015). Dois ângulos para uma análise da projeção regional brasileira: a visão do Departamento de Estado norte-americano e a questão brasiguaia. $P a-$ pel Político, 2O(2), 565-583. http://dx.doi. org/10.11144/Javeriana.papo20-2.daua 


\section{Introdução}

Este texto problematiza o sentido da projeção regional brasileira na atualidade, examinando elementos referidos a polaridades opostas do ponto de vista do poder político e econômico em relação ao Brasil: de um lado, a visão dos Estados Unidos, país que exerce hegemonia econômica, política, cultural e diplomática sobre o Brasil. De outro lado, a crise política recente no Paraguai, país que tem uma relação histórica de dependência em relação ao Brasil, acentuada sob a ditadura de Alfredo Stroessner (1954-1989).

Para alcançar este objetivo, o artigo realiza o seguinte movimento. Inicialmente é abordado o contexto em que ressurgem projetos de integração regional americana nos anos 1990, referindo a proposição original da Iniciativa para a Integração Regional Sul-Americana (IIRSA) em 2000 e a constituição da União de Nações Sul-Americanas (UNASUL) em 2008 ao movimento de abertura econômica multilateral que caracteriza a chamada globalização. Nesta conjuntura, inscreve-se a polêmica em torno do sentido da integração sul-americana comandado pelo Brasil no curso das gestões petistas, questão que é examinada na sequência a partir de ângulos opostos.

Primeiramente, são analisados pronunciamentos emanados do Departamento de Estado dos Estados Unidos relacionados ao tema, visando amealhar elementos que evidenciem como o atual protagonismo regional brasileiro é encarado pelo poder hegemônico no continente e no mundo. A seguir são analisadas as relações entre o estado brasileiro e o Paraguai, um dos países mais pobres e desiguais do continente, e no qual a influência regional brasileira se expressou de modo pioneiro desde o século XIX. O foco da análise é a questão dos brasiguaios, metonímia a partir da qual é conhecido o poderoso setor de proprietários rurais de origem brasileira radicados no Paraguai, que ganhou protagonismo regional a partir do recente boom da soja. Em particular, examinam-se os paradoxos da diplomacia brasileira evidenciados na crise política que levou à deposição do presidente Fernando Lugo em junho de 2012. Assumimos como premissa que a aproximação entre o modo como a projeção regional brasileira é interpretada pelo poder hegemônico no continente, e a incidência deste movimento em um país no qual a influência brasileira está histórica e economicamente enraizada, oferece indícios relevantes para avaliar o sentido da integração regional liderada pelo Brasil no subcontinente na atualidade. Nossa hipótese é que, ao contrário da noção difundida pelas gestões presidenciais do Partido dos Trabalhadores no Brasil (Lula da Silva, 2003-2010; Dilma Roussef, 2011-2014) este processo não contradiz o interesse dos Estados Unidos, nem aponta para um novo desenvolvimentismo (Mercadante, 2010; Mattei, 2011), mas promove uma modalidade de integração que reproduz as assimetrias que caracterizam o capitalismo contemporâneo. Assim, em última análise, a polêmica em torno do caráter do projeto de integração regional em curso no subcontinente remete a uma apreciação sobre o sentido das gestões presidenciais petistas no Brasil. 


\section{O Brasil e a integração regional contemporânea}

Em um movimento que se confunde com a própria globalização, a aceleração das tendências à financeirização do capitalismo pressionou por uma abertura econômica multilateral no contexto do colapso soviético, associada à difusão da agenda política identificada com o neoliberalismo, em um processo cuja racionalidade reforçou a liderança geopolítica dos Estados Unidos e culminou com a institucionalização de um regime multilateral de comércio referido a Organização Mundial do Comércio (OMC) em 1994 (Brenner, 2003; Gowan, 2003; Panitch \& Gindin, 2006). Projetos de integração regional voltaram ao debate político nesta conjuntura, que assistiu a formação de blocos econômicos nos marcos da concorrência intracapitalista, como a APEC (Asia- Pacific Economic Cooperation (1989) e a União Europeia (1992). Expressão regional deste movimento, a assinatura do NAFTA (North American Free Trade Agreement) em 1994 e o processo que levou a constituição da UNASUL em 2008 está referida a este contexto adverso às forças populares, cujas linhas gerais é preciso reconstituir.

Em 1990, no momento em que se desmanchava a União Soviética, o presidente George Bush (pai) lançou a 'Iniciativa para as Américas', uma proposta de integração regional balizada pelo tripé livre comércio, fluxo de investimentos e pagamento da dívida externa, prevendo uma integração comercial hemisférica, excluindo Cuba. Em 1994, na $1^{\text {a }}$ Cúpula das Américas em Miami a proposta materializou-se no projeto da ALCA (Área de LivreComércio das Américas), que deveria ser implementada até 2005. Simultaneamente, entrou em vigor um acordo de livre comércio entre Estados Unidos, México e Canadá em 1994, o NAFTA. Entretanto, a proposta da ALCA enfrentou resistências do estado e de amplos setores da sociedade no Brasil e em outros países latino-americanos, resultando no fracasso da iniciativa, consumado na V Cúpula das Américas em Mar del Plata em 2005. A partir de então, os Estados Unidos adotaram como estratégia a assinatura de tratados bilateriais de livre-comércio, firmando acordos com países centro-americanos, Chile, Colômbia e mais recentemente, o Peru, ao mesmo tempo em que aprofundaram as dimensões que lhes interessavam na integração regional, principalmente relacionadas à segurança, por meio de iniciativas como a ASPAN (Aliança para a Segurança da América do Norte). Se o NAFTA e seus desdobramentos são identificados com uma integração subordinada, unanimemente condenada pelo campo popular no continente ${ }^{1}$, o processo que levou a constituição da UNASUL está marcada por ambiguidades que devem ser ponderadas.

Ao consumar-se o atrelamento da política mexicana aos Estados Unidos em meados dos anos 1990, a diplomacia brasileira visualizou progressivamente a América do Sul como referência geográfica de um projeto de liderança regional. Esta perspectiva

\footnotetext{
${ }^{1}$ Uma boa análise a respeito é Arroyo, 2009.
} 
materializou-se em uma aproximação entre o Mercosul e a CAN (Comunidade Andina das Nações), como uma estratégia para a constituição de um bloco econômico alternativo no espaço sul-americano. É neste contexto que surgiu, durante o governo de Fernando Henrique Cardoso, a proposta da IIRSA, sinalizando para uma integração sul-americana referenciada no que a Comissão Econômica para a América Latina (CEPAL) descreveu neste momento como um 'regionalismo aberto' - uma modalidade de integração regional orientada à abertura comercial multilateral.

A IIRSA constituiu-se como um mecanismo institucional de coordenação de ações dos doze países da América do Sul, com o objetivo de construir uma agenda comum de infraestrutura nas áreas de transportes, energia e comunicações. De um ponto de vista logístico, o subcontinente é dividido em nove Eixos de Integração e Desenvolvimento, que muitas vezes se sobrepõem geograficamente, segundo uma lógica de integração da infraestrutura orientada à circulação de mercadorias. Assim, a IIRSA se materializa em um conjunto de projetos de integração da infraestrutura regional: o relatório de 10 anos da iniciativa, publicado em 2011, enumerava 524 projetos, com investimento estimado em 96 bilhões de dólares distribuídos em 47 grupos vinculados aos 9 Eixos de Integração e Desenvolvimento. Esta agenda inclui cerca de 30 megaprojetos em curso, incorporando obras como o metrô de grandes cidades como Caracas, corredores fluviais, rodovias e ferrovias transnacionais, além de numerosas hidroelétricas. As obras são financiadas por órgãos de financiamento multilateral como o Banco do Sul, Corporação Andina de Fomento (CAF), Banco Nacional de Desenvolvimento Econômico e Social (BNDES) e o Banco Interamericano de Desenvolvimento (BID), e são executadas, na maior parte, por empreiteiras brasileiras de atuação internacional (IIRSA, 2011).

Proposta em uma cúpula de presidentes sul-americanos em Brasília em 2000, originalmente pensada como a dimensão de infraestrutura de um projeto de integração regional referenciada no regionalismo aberto, a IIRSA foi repaginada pelo governo Lula, que a incorporou ao Conselho de Infraestrutura e Planejamento (COSIPLAN) da UNASUL, convertendo-a no esteio material desta organização. Para justificar este movimento, os defensores da gestão petista alegam uma inflexão na orientação da política externa brasileira, em sintonia com a ascensão de governos progressistas de diferentes matizes entre o final dos anos 1990 e o início do século XXI no continente, questionando as políticas neoliberais domésticas e regionais prevalentes. Neste contexto, o estado brasileiro teria abandonado o regionalismo aberto característico dos anos anteriores em nome de uma política que enfatiza a integração sul-americana como estratégia de inserção internacional soberana, descrita como 'regionalismo desenvolvimentista' ou 'pós-neoliberal'. Nesta perspectiva, sugere-se que esta modalidade de integração promoverá “a integração física entre os interiores dos países, passo fundamental para a integração de cadeias produtivas de fornecedores e produtores relacionados, objetivando 
a formação de economias de escala e a própria integração das sociedades sul-americanas” (Desidera \& Teixeira, 2012, p. 32).

No entanto, esta proposição tem sido problematizada por múltiplas evidências políticas, que incluem o paradoxo vivenciado pela diplomacia brasileira na crise que culminou na deposição do presidente Fernando Lugo no Paraguai em 2011, além dos numerosos conflitos socioambientais envolvendo a expansão das empreiteiras brasileiras no continente, apoiada na atuação controversa do BNDES, o que levou um analista a descrever a IIRSA como uma espécie de PAC (Programa de Aceleração do Crescimento) para a América do Sul. Nesta perspectiva, esta modalidade de integração é vista como um processo de organização do território em unidades de negócio, no qual a IIRSA constitui "uma metodologia de repasse de recursos naturais, mercados potenciais e soberania a investidores privados, em escala continental, com respaldo político e segurança jurídica” (Novoa, 2011) . No plano teórico, ressurgem reflexões que resgatam, de modo explícito ou não, as proposições de Rui Mauro Marini nos anos 1970, apontando para o que este autor descreveu como um "subimperialismo brasileiro" (Marini, 2000).

Em última análise, a polêmica em torno do caráter da IIRSA redunda em uma apreciação sobre o sentido das gestões presidenciais petistas no Brasil. Em um extremo deste debate, o projeto petista é referido a uma América Latina que se teria constituído como um 'oasis antineoliberal' no início do século XXI (Sader, 2010). No polo oposto, perspectivas críticas enfatizam o "caráter ultraconservador do governo Lula" (Sampaio Jr., 2006), ou de modo mais condescendente, o interpretam como variação de um fenômeno descrito como 'izquierda consentida', caracterizado pela complacência de governos identificados originalmente com a esquerda, em relação ao neoliberalismo e ao imperialismo (Webber \& Carr, 2013). Diante destas leituras contrastantes, que estão referidas a percepções divergentes sobre a dinâmica das relações entre o Brasil e os Estados Unidos na atualidade, é pertinente examinar como o próprio Departamento de Estado deste país interpreta o protagonismo regional brasileiro, para então analisar os efeitos desta projeção em um caso concreto, a crise política recente no Paraguai.

\section{A América Latina segundo o departamento de Estado dos Estados Unidos}

Em uma pesquisa preliminar visando localizar documentos em que se expresse a visão do Departamento de Estado dos Estados Unidos sobre temas relacionados à Amazônia e a integração sul-americana, foram consultados pronunciamentos públicos de seus funcionários no banco de dados desta instituição². Esta experiência sugeriu algumas

\footnotetext{
${ }^{2}$ Esta pesquisa inicial foi realizada nos marcos do projeto "Estrutura Socioeconômica e Políticas para a Integração da América do Sul", do IPEA (Instituto de Pesquisa Econômica Aplicada), e será aprofundada pelo autor.
} 
percepções sobre a relação que este país tem com a região na atualidade, referenciando o marco no qual se inscreve a relação com o Brasil.

Englobada com o Canadá e o Caribe sob a rubrica de 'Hemisfério Ocidental' (Western Hemisphere) constata-se, em primeiro lugar, que a América Latina não ocupa um lugar protagonista nas preocupações do Departamento de Estado no presente, em contraste com países como Afeganistão, Haiti, Irã, Iraque, Israel e China, que recebem atenção política específica e detalhada -por exemplo, são temas de ‘Policy Issue'. No continente, há dois países que recebem um número de referências muito superior aos demais, México e Colômbia. Esta constatação indica que a intervenção estadunidense no combate às drogas corresponde a uma intensificação das relações em todos os níveis, ou vice-versa. Assim, é notável que ambos países assinaram tratados de livre-comércio com os Estados Unidos e adotaram planos antidrogas de matriz similar, o Plan Colombia e o Plan Merida, ostensivamente assessorados pela potência continental. Além destes países, há referência recorrente a Cuba em declarações oficiais, repetindo como um mantra a ideologia de defesa da liberdade e da democracia. De modo análogo, a Venezuela e o então presidente Hugo Chávez são frequentemente assunto de perguntas jornalísticas aos representantes de Estado, cujas respostas ecoam motivos similares.

Do ponto de vista temático, os discursos oficiais que acessamos são quase sempre genéricos, e referidos ao tripé 'comércio, democracia e drogas' ('trade, democracy and drugs'). A questão ambiental emerge subordinada à economia e não aparece como uma preocupação fundamental, em contraste com o combate ao terrorismo, drogas, democracia e livre-comércio. Dentre os temas que merecem políticas específicas do Departamento de Estado, segurança alimentar, mudança climática e segurança energética são os mais próximos, mas seu tratamento é associado à economia e ao livre-comércio. Em suma, meio ambiente e livre-comércio mostram-se indissociados nas propostas e discursos do Departamento de Estado norte-americano.

No plano dos projetos de integração regional, a IIRSA é escassamente mencionada. No entanto há diversas referências à UNASUL, sempre simpáticas a este projeto de associação continental e ao protagonismo brasileiro. Em 2005, antes mesmo da constituição desta organização regional, a então secretária de Estado norte-americana Condoleeza Rice pautou o papel que os Estados Unidos delineavam para o Brasil:

Nosso desafio agora é usar o poder da nossa parceria democrática para dois grandes propósitos: entregar os benefícios da democracia a todos os nossos cidadãos... e sustentar todos os povos que desejam uma mudança democrática - onde quer que eles vivam no globo. 
Nesta missão, os Estados Unidos encaram o Brasil como um líder regional - e um parceiro global ${ }^{3}$ (Rice, 2005)

Alguns anos depois, às vésperas da formalização da UNASUL, Rice ratificou o apoio estadunidense ao protagonismo brasileiro nos marcos de um projeto de integração regional. Questionada sobre a iniciativa brasileira de criar um Conselho de Defesa Sul-Americano, instância relacionada aos assuntos de segurança no âmbito esta organização, a então secretária de Estado declarou:

Bem, eu sou completamente a favor da cooperação regional em nível regional, subregional ou em qualquer nível que possamos atingir. [...] Assim, eu não apenas não tenho um problema com isso (criação de um Conselho de Defesa Sul-Americano) como eu confio na liderança brasileira e anseio em coordenar com ela. O que nós não queremos, é claro, é que o hemisfério como um todo não possa cooperar. Mas eu acho que nós temos muitos meios pelos quais isso pode acontecer. E eu deixarei ao Brasil e aos outros quem devem ser os membros deste esforço4. (Rice, 2008)

Neste mesmo ano de 2008, Barack Obama foi eleito presidente dos Estados Unidos pelo Partido Democrata e Hilary Clinton, derrotada por Obama nas prévias do partido, assumiu a secretaria de Estado. Em um discurso na Assembleia da OEA (Organização dos Estados Americanos) em Lima, Clinton revela a continuidade da linha política encampada por sua antecessora:

Nós acreditamos que é do interesse nacional dos Estados Unidos e de todas as nações aqui
representadas promover a colaboração pragmática e produtiva entre os membros da comu-
nidade das Américas. É por isso que damos as boas-vindas a parcerias multilaterais como
a UNASUL, o CARICOM e a SICA, e ao objetivo do Conselho Sul-Americano de Defesa de

3 "Our world is moving toward greater freedom and democracy. And President Bush has outlined the charge of our times: Those of us who are on the right side of freedom's divide have an obligation to those who are still on the wrong side of that divide. Our challenge now is to use the power of our democratic partnership for two great purposes: to deliver the benefits of democracy to all of our citizens [...] and to support all peoples who desire democratic change - wherever they may live on this globe. In this mission, the United States looks to Brazil as a regional leader - and a global partner" (Rice, 2005).

4 "Well, I am all for regional cooperation at the regional, subregional, whatever level we can attain it. (...) So I not only have no problem with it, I trust Brazil's leadership and look forward to coordination with it. What we don't want, of course, is that the hemisphere as a whole cannot cooperate. But I think we have many means by which that can happen. And I'll leave to Brazil and others who the members of those efforts might be." (Rice, 2008). 
promover uma maior confiança entre seus membros e uma cooperação mais efetiva para assegurar a segurança em relação ao crime organizado e ao terrorismo5. (Clinton, 2010)

Como explicou um alto funcionário do Escritório de Assuntos do Hemisfério Ocidental, esta linha política revela uma nova abordagem dos Estados Unidos em relação ao multilateralismo no hemisfério, ao reconhecer que vínculos com agrupamentos regionais, como a UNASUL e a Comunidade do Caribe (CARICOM), são condizentes com a estratégia hegemônica do país no continente (Shannon Jr., 2009).

No entanto, assim como no Brasil há os entusiastas em relação à projeção regional do país, vislumbrando um desafio à hegemonia secular estadunidense no 'hemisfério', também nos Estados Unidos há vozes receosas de que o subcontinente em breve será

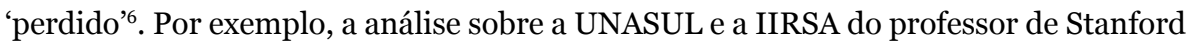
Thomas Andrew O'Keefe conclui que “vislumbra-se no horizonte a fantasia de gerações de esquerdistas e nacionalistas latino-americanos: o fim da hegemonia americana no hemisfério ocidental” (O’Keefe, 2011, p. 52). Segundo esta análise, os Estados Unidos ocupam no presente uma posição equivalente ao Reino Unido no entreguerras. Ligado ao Departamento de Estado como o próprio O'Keefe, Philip Goldberg, no comando do Escritório de Pesquisa e Inteligência, referencia a constituição da UNASUL a um esforço para diminuir a influência diplomática estadunidense, mas opina que "a habilidade destas organizações nascentes de minar a influência estadunidense não deve ser superestimada" (Goldberg, 2011).

Apesar destas leituras, as declarações que emanam do Departamento de Estado não revelam qualquer ambiguidade. Em 2012, após uma visita a México, Colômbia e Brasil, a Sub-Secretária de Assuntos Políticos (Under Secretary for Political Affairs) Wendy Sherman, terceiro cargo na hierarquia do departamento, pronunciou uma conferência no "Council of the Americas and the Center for Strategic and International Studies" (CSIS) em Washington. Diferentemente de outras falas citadas, esta conferência dirigiu-se a um público interno e revela um empenho em dissipar receios sobre a posição estadunidense em relação ao Brasil.

\footnotetext{
5 "We believe it is in the national interest of the United States and of every nation represented here to promote pragmatic and productive collaboration among members of the community of the Americas. That is why we welcome multilateral partnerships like UNASUR and CARICOM and SICA and the South American Defense Council's goal of promoting greater confidence among its members and more effective cooperation to ensure security from organized crime and terrorism." (Clinton, 2010).

${ }^{6}$ Sobre a noção de que os Estados Unidos 'perdem' países, ver Said (1981).
} 
Em Brasília, minhas reuniões no Ministério do Exterior, no escritório do presidente e no congresso foram uma oportunidade para avaliar uma parceria já forte no século XXI e que parece ganhar amplitude e profundidade a cada dia. (...) Hoje o Brasil é um parceiro estratégico para endereçar questões globais -não somente hemisféricas- de preocupação mútua. E eu quero ser clara que os Estados Unidos precisam e dão as boas-vindas ao papel expandido positivo do Brasil7. (Sherman, 2012)

Considerando que a diplomacia estadunidense contemporânea expressa suas posições com clareza crua e frequentemente maniqueísta, os pronunciamentos analisados revelam uma notável discrição em temas concernentes a integração sul-americana, ocasionalmente permeados por certo entusiasmo em relação ao protagonismo brasileiro, sugerindo que o sentido em que avança este processo não é identificada como uma ameaça ou uma contradição aos interesses dos Estados Unidos na região.

\section{Soja, agronegócio e a questão brasiguaia no Cone Sul}

Se as declarações de funcionários do estado norte-americano oferecem elementos sobre a percepção neste país em relação ao sentido da integração sul-americana, a análise do papel do estado brasileiro em relação aos brasiguaios evidencia um paradoxo da diplomacia nacional, na medida em que há numerosos indícios de apoio a um dos grupos de poder que, intrinsecamente ligado às multinacionais do agronegócio, conspirou para a destituição de um aliado político no subcontinente.

A origem da problemática brasiguaia está referida a confluência de dois vetores da história paraguaia independente: a questão agrária e a influência do Brasil sobre o país. Em uma perspectiva histórica, ambos fenômenos estão relacionados ao desenlace da Guerra da Tríplice Aliança (1865-1870), episódio decisivo na formação do Paraguai contemporâneo, e que incidiu nas relações sociais no campo assim como na inserção internacional do país. Em sua expressão presente, a constituição do poder brasiguaio remete à convergência de interesses econômicos e geopolíticos entre a ditadura comandada por Alfredo Stroessner (1954-1989) e a política externa brasileira no período (Santos, 2014).

Embora a massiva presença brasileira em território paraguaio não seja um fenômeno recente, os conflitos envolvendo brasiguaios tem se multiplicado no contexto da expansão do cultivo da soja no último decênio, nos marcos de um modelo produtivo dominado por corporações transnacionais. Estima-se que em 1973 a oleoginosa ocupava

\footnotetext{
7 "In Brasilia, my meetings at the Foreign Ministry, the President's office, and the Congress were a chance to take stock of an already strong 21st Century partnership that seems to be gaining breadth and depth by the day. (...) Today Brazil is a strategic partner in addressing global -not just hemispheric- issues of shared concern. And I want to be clear that the United States needs and welcomes Brazil's positive expanded role." (Sherman, 2012).
} 
40 mil hectares no país. Em 1996 a superfície plantada aproximava-se de 1 milhão de hectares. Com a introdução de sementes transgênicas no final do decênio, calcula-se que a fronteira da soja avançou em média 125 mil hectares por ano nas safras seguintes, alcançando 2,8 milhões de hectares no ciclo agrícola de 2010/11 (Palau, 2012, pp. 33-347). Em 2012, as projeções da Monsanto, uma das maiores empresas do agronegócio mundial, apontam que se ultrapassará os 3 milhões de hectares plantados, embora as toneladas produzidas indiquem uma redução da produtividade. Neste período, o país manteve altas taxas de crescimento, rompendo com a letargia prevalente desde a construção de Itaipu: em 2010 por exemplo, o ritmo da expansão da economia paraguaia só ficou atrás do Catar. Atualmente, o Paraguai é o quarto exportador mundial de soja e o oitavo de carne bovina.

A expansão concomitante da soja e da pecuária em um contexto em que se esgotava a disponibilidade de terras do Estado (as chamadas 'tierras fiscales'), acirrou as contradições entre o agronegócio e os modos de vida de orientação camponesa, além de causar devastação ambiental no oriente do país e no Chaco, onde encontra-se ameaçado por exemplo, um dos últimos grupos aborígenes que vive em isolamento voluntário no continente, os ayoreo.

No caso específico da soja, produto responsável pela maior receita dentre as exportações paraguaias, sua expansão implica na adoção de um modelo de negócio associado a um pacote tecnológico promovido pelas corporações transnacionais, que determina a forma como se produz a commodity em questão. Como no Brasil, o mercado é dominado pela semente transgênica resistente ao herbicida Roundup (glifosato), ambos patenteados pela Monsanto. Este pacote tecnológico está atrelado à técnica do plantio direto, em que os processos de arar e limpar o solo são substituídos pela aplicação de produtos químicos, cuja eficácia exige o seu uso em quantidade crescente. A maior economia associada ao plantio direto é a redução de mão-de-obra empregada, calculada em duas pessoas por cada mil hectares por ano, em um modelo produtivo viável somente para o cultivo em grande escala. Esta intensificação da agricultura é comparada por autores como Javiera Rulli a "una agricultura extractivista, una minería en el suelo agrícola”, em uma realidade na qual "el paquete de la soja implica la descampesinización absoluta, se trata de una agricultura sin agricultores" (Rulli, 2007, pp. 18-20). No outro polo do processo, transnacionais como Cargill, ADM e Bunge açambarcam e exportam a soja produzida, o que levou um autor a concluir que "en la práctica, los productores son solo un engrenaje entre el proceso de provisión y el acopio de la produción (...)” (Rojas, 2009, p. 73).

Os impactos socioambientais da expansão da soja no Paraguai são documentados e denunciados regularmente por organizações vinculadas aos movimentos camponeses e indígenas ${ }^{8}$. As consequências registradas incluem: expropriação de pequenos produtores

\footnotetext{
${ }^{8}$ Uma visão abrangente da questão é apresentada em Palau et al., (2007).
} 
por meio de múltiplos mecanismos; graves danos à saúde e ao meio ambiente em função das fumigações de agrotóxicos; aumento do desemprego, do êxodo rural e da emigração; maior concentração da terra; ameaça à soberania alimentar; avanço direto sobre áreas virgens, mas também indireto, como consequência do deslocamento da fronteira pecuária; potencial desertificação do solo em função da siembra directa; contaminação do aquífero Guarani (Palau et al., 2007). Neste contexto, a expansão do cultivo da soja enfrenta a resistência do conjunto de atores sociais identificados com a democratização das relações de produção no campo e a preservação do meio ambiente, e que se opõem ao avanço das corporações transnacionais.

É notório o protagonismo de empresários rurais brasileiros na expansão do agronegócio no Paraguai. Embora não haja estatísticas precisas, Marcos Glauser cruzou dados oficiais do INDERT (Instituto Nacional de Desarrollo Rural y de la Tierra) com a intenção de estimar a quantidade de terras de propriedade estrangeira no país. Seu trabalho revela que cerca de $1 / 5$ das terras nacionais estão em mãos estrangeiras, dentre as quais cerca de $2 / 3$ pertencem a brasileiros, o que equivale a 4.792.528 hectares (Glauser, 2009, p. 35). Uma vez que a área agricultável do país é calculada em 24 milhões de hectares, estima-se que os brasileiros possuem em torno de $1 / 5$ das melhores terras, dentre as quais incluem-se cerca de $40 \%$ da área dedicada à soja no país. A apropriação de terras por estrangeiros em larga escala também foi denunciada recentemente na Argentina e na Bolívia, para citar exemplos na região (Klipphan \& Enz, 2006; Urioste, 2011), mas o papel singular que a reivindicação dos derrotados na Guerra da Tríplice Aliança teve para a afirmação do nacionalismo paraguaio torna a preponderância brasiguaia um tema particularmente sensível.

Segundo analistas paraguaios como Fogel, a especificidade da situação do país em relação a outros exportadores de soja da região radica na ínfima integração do agronegócio às demais cadeias produtivas nacionais, fenômeno acentuado pelas características da inserção brasiguaia. De um modo geral, a baixa pressão fiscal sobre o agronegócio, que ainda se beneficia de um significativo subsídio ao combustível utilizado na lavoura, minimiza as possibilidades de intervenção estatal em um sentido redistributivo. A exportação de um alto percentual de soja em grão, inclusive para o Brasil, reduz o potencial dinamismo econômico derivado do processamento da commodity no país. Como um agravante da situação, admite-se que a produção de soja comandada por brasiguaios envolve operações de contrabando em grande escala, principalmente através da fronteira seca em que sua presença é dominante, impactando negativamente na arrecadação tributária e na balança comercial do país:

El referido ingreso irregular de equipos y maquinarias por parte de las nuevas empresas brasileñas, sin los controles pertinentes, se proyecta en el hecho que el Paraguay sea, conforme a registros de la Comisión Económica para América Latina (CEPAL), el país al que 
menos inversiones viene en el continente, considerando el período 1990-2003, registrándose incluso una desinversión en el 2002. En esta dinámica que podría calificarse como clandestina, los empresarios del Brasil, vienen con sus propias maquinarias, sus propios tractores que después, eventualmente los vuelven a llevar al Brasil, de modo que técnicamente no hay inversión. Los tributos irrisorios a la exportación también son evadidos, en parte por los sojeros, estimando algunas fuentes en un millón de toneladas la soja que salió de contrabando en la última campaña agrícola. (Fogel, 2005, p. 65)

Considerando o caráter dos nexos estabelecidos entre os grandes proprietários brasiguaios com o espaço econômico paraguaio, no bojo de um negócio transnacional em que constituem uma engrenagem, somada à impermeabilidade de seus protagonistas às instituições sociais e culturais do país vizinho, analistas consideram que a produção da soja constitui uma modalidade de economia de enclave em território paraguaio (Fogel \& Riquelme, 2005). Neste sentido, Fogel indica que:

[...] debe resaltarse en el análisis de la expansión de los sojeros brasileños, la dinámica del espacio fronterizo centrada en el brasiguayo, que responde más a relaciones y pautas del Brasil del cual depende, que de relaciones internas a nuestro Estado nación (Paraguay). (Fogel, 2005, p. 97)

Os vínculos que unem o espaço econômico brasiguaio à dinâmica do agronegócio no Brasil são referendados por uma recente pesquisa intitulada "Los actores del agronegocio en Paraguay", em que Luis Rojas analisou uma amostra das principais empresas envolvidas com o setor no país. Enfatizando que "la columna vertebral del agronegocio en el país constituyen las corporaciones transnacionales [...] que determinan en última instancia qué y como se va a producir [...]”, Rojas descreve a atuação de outras 9 empresas estrangeiras, dentre as quais 3 são brasileiras, além de analisar outras 28 empresas consideradas nacionais, sobre as quais conclui: "De las 28 empresas nombradas, al menos 14 son propiedad, total o parcialmente, de brasileños (o brasiguayos), lo que representa el 50\% de esta muestra de empresas locales" (Rojas, 2009, pp. 52-53).

Ao revelar a maciça presença de brasileiros nas principais empresas que atuam no Paraguai conectadas às corporações transnacionais, a investigação indica que protagonistas do setor têm negócios em ambos lados da fronteira, sugerindo vínculos próximos entre os atores do agronegócio nos dois países, que não se resumem à esfera das transnacionais que vertebram a atividade. Uma decorrência desta constatação é que a afinidade entre os setores que pressionam em favor do agronegócio no Brasil e no Paraguai pode ir além do interesse comum, pois em muitos casos, trata-se das mesmas empresas e pessoas. Diante desta realidade é plausível supor que, se o governo brasileiro 
mostra-se suscetível às pressões do agronegócio em seu território, isto repercutirá no sentido da influência exercida em um país vizinho. É neste contexto que se compreende o estímulo prestado à sua expansão internacional por meio do BNDES, como tem ocorrido no campo da construção civil, apoiando estes interesses em uma região que pretende sob sua esfera de influência:

En mayo de 2007, la visita del Pdte. Lula en el marco del Seminario de Agrocombustibles Brasil-Paraguay, concluyó con la firma del memorándum de entendimiento. El presidente brasileño estuvo acompañado de 30 empresarios y los alentó a que invirtieran en el Paraguay. El Banco Nacional de Desarrollo Económico y Social (BNDES) de Brasil, anunció en dicho Seminario que contará con una línea de crédito específica para financiar a empresarios brasileños que decidan invertir en agronegocios en Paraguay. (BASE IS, 2010, p. 10)

\section{República Unida de la Soja e a destituição de Lugo}

A multinacional do agronegocio Syngenta veiculou em 2003 uma peça publicitária em que se desenhava uma 'República Unida de la Soja', abarcando territórios de Argentina, Bolívia, Brasil e Paraguai (Rulli, 2007). As reações que despertou entre aqueles que se opõem à expansão da oleaginosa na região sugere que o anúncio dialogava com uma percepção generalizada sobre o poder das transnacionais do agronegócio, uma engrenagem produtiva que tem nos empresários dedicados à plantação a sua face mais visível.

Elo mais fraco na cadeia do agronegócio em função da sua condição dependente, os proprietários rurais protagonizam os conflitos sociais decorrentes da privação de um meio de vida para a população camponesa, que a expansão da sua atividade implica. Na medida em que adquirem terras nos diversos países da região, sua atuação tende igualmente a transcender as fronteiras nacionais e como no caso das corporações a que se atrelam, contam com o apoio do aparelho estatal para assegurar o bom andamento de seus negócios. Isto pode significar, no caso de proprietários rurais de origem brasileira que expandem seus empreendimentos na direção do Paraguai e da Bolívia, a defesa dos seus interesses pela representação diplomática do Estado brasileiro, uma atuação sugerida pelos dois polos do problema: os empresários do agronegócio e aqueles que lutam pela reforma agrária. Nilson Medina, considerado o maior empresário rural brasileiro na Bolívia, refere-se a este apoio em uma entrevista:

Agora, nós, Heloisa, temos a garantia do governo brasileiro, sabe, eu acho que, assim como os "brasiguaios" têm a garantia do governo brasileiro, quando acontece alguma coisa lá existe uma intervenção, eu acredito que nós vamos ter a mesma atenção. $O$ governo, o Celso Amorim, ele veio exclusivamente pra falar com a gente; o Celso Amorim, que eu acho um espetáculo o Celso Amorim, então, eu acho que, se acontecer alguma coisa aqui 
na Bolívia, o governo imediatamente vai intervir, e aí o Lula chama o Evo e fala: "Olha, a propriedade do Nilson Medina foi invadida, ele tem tudo certo, ele cumpre a função social e tudo [...] (Gimenez, 2010)

Uma vez que o mais importante plantador de soja brasileiro na Bolívia evoca o exemplo dos brasiguaios como um precedente que afiança a sua situação sob o governo de Evo Morales, uma conjuntura certamente mais conflituosa do que o governo Lugo, infere-se que a atuação da diplomacia brasileira em defesa dos seus interesses é vista como um dado da realidade pelos empresários do setor. O mesmo Medina relata um episódio em que, durante a campanha presidencial de Morales, expressou ao então ministro da Agricultura do governo Lula, Roberto Rodrigues, preocupação em relação à possibilidade de desapropriação de brasileiros. Poucos dias depois o embaixador brasileiro no país teria telefonado para tranquilizar Medina, que mais tarde receberia garantias pessoais do próprio Morales (Gimenez, 2010).

No outro lado do espectro político, ex-diretores dos órgãos encarregados de proceder à reforma agrária na Bolívia e no Paraguai, respectivamente sob Morales e Lugo, relatam pressões exercidas pela diplomacia brasileira em defesa do empresariado rural brasileiro ${ }^{9}$. Observadores da questão agrária no Paraguai também registraram uma intercessão recente no curso do conflito de terras em Nacunday, episódio que explicitou os impasses enfrentados pelo governo Lugo em seu último ano. Tratava-se de terras de documentação frágil e procedência duvidosa em região limítrofe com o Brasil, apropriadas para a plantação de soja pelo ícone do poder brasiguaio no país, Tranquilo Favero. Os acampados argumentavam que, além das suspeitas irregularidades na titulação, havia tierras excedentes, ou seja: a superfície abarcada pela propriedade seria superior à documentação registrada em pelo menos 12 mil hectares. Diante desta suspeita, o INDERT decidiu proceder à mensura do terreno, mas houve resistência dos brasiguaios. Com o respaldo de uma autorização judicial e de tropas, iniciaram-se os trabalhos mas, pouco depois, um segundo magistrado cassou o mandato original e o juiz que inicialmente o concedeu, foi punido. Neste contexto, observadores registraram a intervenção da diplomacia brasileira:

El gobierno de Brasil se interesó por el caso Ñacunday ante la inseguridad que podrían encontrarse las familias de brasiguayos. El interés del gobierno se manifestó en diversas acciones: el Cónsul adjunto del Brasil en Ciudad del Este, junto a abogados de productores y un asesor jurídico del Consulado brasileño, recorrieron la zona de Nacunday a fin de

\footnotetext{
${ }^{9}$ Para o relato de Alcides Vadillo, ex-diretor do INRA (Instituto Nacional da Reforma Agraria), consultar o anexo da dissertação de Heloísa Gimenez citada. Alberto Alderete, ex-diretor do INDERT no Paraguai, afirmou com clareza que sofreu pressões do governo brasileiro durante sua gestão em entrevista ao autor em agosto de 2012.
} 
interiorizarse de la situación y el propio embajador de Brasil realizó una visita “de cortesía” al presidente del INDERT. (Programa Democratización y Construcción de la Paz, 2012, p. 5)

Ao final as terras não foram recuperadas, o INDERT sofreu intervenção do governo federal em meio a acusações de corrupção de seu terceiro diretor e os camponeses se retiraram, em um desfecho que referenda a observação de Fogel: “[...] nuestro Estado no ejerce control sobre la población de brasiguayos ni sobre sus bienes” (Fogel, 2005, p. 95). Parte dos acampados de Nacunday transferiram-se à Curuguaty, palco dos trágicos eventos que serviram de pretexto para desencadear o julgamento de Lugo alguns meses depois.

Embora haja indícios convincentes de que a destituição do presidente foi precipitada por motivações políticas imediatistas (Santos, 2013), o poder brasiguaio é parte dos atores que confluíram com o interesse das multinacionais do agronegócio, da Rio Tinto Alcan, do Departamento de Estado dos Estados Unidos, de pecuaristas e traficantes diversos para favorecer a aliança tática entre liberais e colorados que consumou o golpe. Nesta perspectiva, o dilema paraguaio expressou um paradoxo da influência brasileira na região, na medida em que o apoio ao empresariado rural brasiguaio enrijeceu os óbices enfrentados pelo governo Lugo para avançar ações mínimas de democratização do acesso à terra, enfraquecendo sua posição diante de interesses que desencadearam um processo de impeachment que a diplomacia brasileira foi então, impotente para frear.

\section{Conclusão}

Aceitando como premissa que os Estados Unidos são o núcleo político, econômico e cultural do imperialismo na contemporaneidade, infere-se que qualquer projeto nacional ou regional endossado por este estado não representa uma ameaça ao padrão de relações internacionais vigente. Ao contrário, os dramáticos acontecimentos recentes no Paraguai sugerem que, sob o verniz de um 'player' na disputa por um mundo multipolar, revela-se um estado brasileiro a serviço da expansão de determinados setores capitalistas internacionalizados na América do Sul, como as empreiteiras e o agronegócio, por meio de uma modalidade de integração voltada à constituição de corredores de exportação de commodities, tais como a soja, o etanol e minérios e que aponta, em última análise, para uma reprimarização da economia do sub-continente sob a liderança regional brasileira funcional ao movimento do capitalismo contemporâneo, comandada desde 2003 pelo Partido dos Trabalhadores.

\section{Referências}

Arroyo, A. (2009). México a 14 años del TLCAN: realidad y propaganda. Em Sandoval, J. M. TLCAN: Balance general e impactos subregionales y sectoriales (pp. 1546). México: Red Mexicana de Acción frente al Libre Comercio, Disponível em: http://www.rmalc.org.mx/documentos/libros/tlcan20o9.pdf. 
BASE IS. (2010). Los impactos socioambientales de la soya en Paraguay. Asunción: Base IS.

Brenner, R. (2003). O boom e a bolha. Os Estados Unidos na economia mundial. Rio de Janeiro: Record.

Clinton, H. R., (2010). Address to the Organization of American States General Assembly. Lima, Peru: National Museum. Disponível em: http://www.state.gov/ secretary/rm/2010/06/142804.htm.

Democratización y Construcción de la Paz, DCP (2012). Monitoreo de la Política de Reforma Agraria del Gobierno Lugo. Síntesis a Diciembre 2011. Asunción: DCP.

Desidera, W., \& Teixeira, R. (2012). La recuperación del Desarrollismo en el Regionalismo Latinoamericano. Em Perspectivas para la integración de América Latina (pp 1-37.). Brasília: CAF; IPEA.

Fogel, R. (2005). Efectos socioambientales del enclave sojero. Em: Fogel, R., \& Riquelme, Q. (Eds.). Enclave soyero merma de soberanía y pobreza. Assunción: CERIS.

Fogel, R. \& Riquelme, Q. (2005). Enclave soyero merma de soberanía y pobreza. Assunción, CERIS.

Gimenez, H. M. (2010). O desenvolvimento da cadeia produtiva da soja na Bolívia e a presença brasileira: uma história incomum. São Paulo. Dissertação de mestrado apresentada no PROLAM-USP.

Glauser, M. (2009). Extranjerización del territorio paraguayo. Asunción: BASE IS.

Goldberg, P. (2011). Emerging Threats and Security in the Western Hemisphere: Next Steps for U.S. Policy. Washington:Bureau of Intelligence and Research Department of State before the House Committee on Foreign Affairs.

Gowan, P. (2003). A roleta global. Rio de Janeiro: Record.

IIRSA (2011). IIRSA 1o anos depois: Suas conquistas e desafios. Buenos Aires: BID, INTAL.

Bartaseghi, L., Ceroni, M., \& Díaz, I. (2006). Infraestructura Regional Sudamericana. Otro paso en la explotación de los pueblos y territorios sudamericanos. Montevideo: Programa Uruguay Sustentable Redes, Amigos de la Tierra.

Klipphan, A., \& Enz, D. (2011). Tierras $S / A$. Cronicas de un pais rematado. Buenos Aires: Alfaguara.

Marini, R. M. (2000). Dialética da dependência. Petrópolis: Vozes.

Mattei, L. (2011). Gênese e agenda do novo desenvolvimentismo brasileiro. IV Encontro Internacional da Associação Keynesiana Brasileira (AKB), Rio de Janeiro. Disponível em: http://www.ppge.ufrgs.br/akb/encontros/2011/10.pdf. 
Mercadante, A. (2010). As bases do novo desenvolvimentismo: análise do governo Lula. Tese Doutorado. Instituto de Economia da Universidade Estadual de Campinas. IE Unicamp, Campinas.

Novoa, L. F. (2011). Brasil, via BNDES reforça caráter regressivo da integração latinoamericana. Entrevista ao Correio da Cidadania, 19/11/2011.

O'Keefe, T. (2011). While the United States Slept, South America Walked. MACLAS (Middle Atlantic Council of Latin American Studies) Latin American Essays, (24), 43-55.

Palau, T., Cabello, D., Maeyens, A., Rulli, J., \& Segovia, D. (2007). Los refugiados del modelo agroexportador. Impacto del monocultivo de soya en las comunidades campesinas paraguayas. Asunción: Base IS.

Palau, T. (2012). Es lógico que una sociedad agredida se defienda. Asunção: BASE IS.

Panitch, L., \& Gindin, S. (2006). Capitalismo global e império norte-americano. Em Panitch, L., \& Leys, Colin (Eds.). Socialist register 2004: O novo desafio imperial (pp. 19-70). Buenos Aires: Consejo Latinoamericano de Ciencias Sociales (CLACSO).

Programa Democratización y Construcción de la Paz.(2012, febrero). Monitoreo de la Política de Reforma Agraria del Gobierno Lugo. Síntesis a Diciembre 2011. Asunción: Programa Democratización y Construcción de la Paz.

Rice, C. (2005). Remarks at the Memorial Museum of Juscelino Kubitschek. Brasilia, Brazil: State Government Secretary. Disponível em: http://2001-009.state.gov/ secretary/rm/2005/45276.htm.

Rice, C. (2008). Remarks With Brazilian Foreign Minister Celso Amorim. Brasilia, Brazil: State Government Secretary. Disponível em: http://2001-2009.state. gov/secretary/rm/2008/03/102228.htm.

Rojas, L. (2009). Actores del Agronegocio en Paraguay. Assunção: BASE IS.

Rulli, J. (2007). Republicas unidas de la soya. Cordoba: GRR.

Sader, E. (2010). A nova toupeira. Os caminhos da esquerda latino-americana. São Paulo: Boitempo.

Said, E. (1981). Covering Islam. Nova Iorque: Pantheon Books.

Sampaio Jr., P. A. (2006). Brasil: As esperanças não vingaram. OSAL (Observatorio Social de América Latina), VI(18), 69-80.

Santos, F. L. B. (2013). A deposição de Lugo e os limites da democracia na América Latina. Cadernos PROLAM/USP, 22, 25-37. 
Santos, F. L. B. (2014). A problemática brasiguaia e os dilemas da projeção regional brasileira. Em Desiderá, W. (Org.). O Brasil e Novas Dimensões da Integração Regional. Brasília: IPEA, (no prelo).

Shannon Jr., T. (2009). Remarks at the 39th Washington Conference of the Council of the Americas. Loy Henderson Conference Room, Washington, DC. May 13, 2009. Disponível em: http://www.state.gov/p/wha/rls/rm/2009/123656.htm.

Sherman, W. (2012). Remarks to the Council of the Americas and the Center for Strategic and International Studies (CSIS). Carnegie Endowment for International Peace. Washington, DC: February 28, 2012. Disponível em: http://www.state. gov/p/us/rm/2012/184853.htm.

Urioste, M. (2011). Concentración y estrangerización de la tierra en Bolívia. La Paz: Fundación Tierra.

Webber, J., \& Carr, B. (2013). The new Latin American left. Cracks in the Empire. Lanham: Rowman \& Littlefield Publishers, Inc. 
